\title{
DESAFIOS DA CONSTRUÇÃO DE UM SISTEMA NACIONAL ARTICULADO DE EDUCAÇÃO
}

\section{CHALLENGES OF BUILDING A NATIONAL ARTICULATED EDUCATION SYSTEM}

\author{
Dermeval Saviani ${ }^{1}$
}

Resumo Busca-se aqui discutir os desafios que se antepõem à tarefa da construção do sistema nacional de educação, no contexto do Plano de Desenvolvimento da Educação, tema retomado por iniciativa do Ministério da Educação. Com base nas imprecisões e confusões reinantes nessa área, começa-se pela discussão do próprio significado da expressão 'sistema nacional' a partir de sua configuração histórica. Em seguida, aborda-se o tema propriamente dito, ou seja, os desafios para a construção do sistema, os quais são agrupados em quatro modalidades: econômicos, traduzidos na tradicional e persistente resistência à manutenção do ensino público no Brasil; políticos, expressos na descontinuidade das iniciativas de reforma da educação; ideológicos, representados pelas idéias e interesses contrários ao sistema nacional de educação; e legais, correspondentes à resistência à aprovação de uma legislação que viabilize a organização do ensino na forma de um sistema nacional em nosso país.

Palavras-chave sistema nacional; educação; plano; financiamento; legislação.
Abstract The purpose of the article is to discuss the challenges that are faced in the task of building the national education system in the context of the Plan for the Development of Education, an issue that has come back under the spotlight by initiative of the Ministry of Education. Based on the inaccuracies and confusion that prevail in this area, the discussion begins with the meaning of the expression 'national system' itself, as based on its historical configuration. It then approaches the theme, i.e., the hurdles that must be overcome to build the system, which are grouped in four modes: economics, translated in the traditional and persistent resistance to maintaining public education in Brazil; political, expressed by the lack of continuity in educational reform initiatives; ideological, represented by ideas and interests that are contrary to the national education system; and legal, involving the resistance against the approval of legislation that may make organizing education as a national system in our country viable.

Keywords national system; education; plan; financing; legislation. 
Não deixa de ser auspicioso o retorno do debate referente ao sistema nacional de educação no contexto brasileiro atual. Trata-se de um tema que pode ser considerado a maior criação da educação ocidental nos séculos XIX e XX. No Brasil, porém, essa questão vem sendo colocada desde o final do século XIX sem jamais conseguir se impor nos debates e, muito menos, viabilizar-se praticamente. Agora, por iniciativa do Ministério da Educação, o tema é retomado no contexto do Plano de Desenvolvimento da Educação (PDE), um programa de metas voltado para o enfrentamento dos problemas que o país vem enfrentando no âmbito da educação básica.

O tema que trato neste texto ${ }^{2}$ diz respeito aos desafios que se antepõem à tarefa da construção do sistema nacional de educação. Considerando as imprecisões e confusões reinantes nessa área, considero conveniente começar pela discussão do próprio significado da expressão 'sistema educacional' a partir de sua configuração histórica. Na seqüência, procurarei abordar o tema propriamente dito, ou seja, os desafios para a construção do sistema, os quais serão agrupados em quatro modalidades: os desafios econômicos, traduzidos na tradicional e persistente resistência à manutenção do ensino público no Brasil; os desafios políticos, expressos na descontinuidade das iniciativas de reforma da educação; os desafios ideológicos, representados pelas idéias e interesses contrários ao sistema nacional de educação; e os desafios legais, correspondentes à resistência à aprovação de uma legislação que permita a organização do ensino na forma de um sistema nacional em nosso país.

\section{Configuração histórica e significado da expressão 'sistema educacional'}

O desenvolvimento da sociedade moderna corresponde ao processo em que a educação passa do ensino individual ministrado no espaço doméstico por preceptores privados para o ensino coletivo ministrado em espaços públicos denominados escolas. Assim, a educação sistematizada própria das instituições escolares tende a se generalizar impondo, em conseqüência, a exigência de se sistematizar também o funcionamento dessas instituições, dando origem aos sistemas educacionais organizados pelo poder público. Com efeito, no referido processo foi se impondo o entendimento de que a educação é uma questão de interesse público, devendo ser situada no âmbito da esfera estatal. Daí a bandeira da escola pública, universal, gratuita, obrigatória e leiga que se difundiu de modo especial a partir da Revolução Francesa. Essa bandeira tornou-se realidade a partir da segunda metade do século XIX com a emergência dos Estados nacionais que se fez acompanhar da implantação dos sistemas nacionais de ensino nos diferentes países como via para a erradicação do analfabetismo e universalização da instrução popular. 
O Brasil foi retardando essa iniciativa e, com isso, foi acumulando um déficit histórico imenso no campo educacional, em contraste com os países que instalaram os respectivos sistemas nacionais de ensino não apenas na Europa, mas também na América Latina, como o ilustram os casos da Argentina, Chile e Uruguai.

O fenômeno dos sistemas nacionais de ensino generalizou, na educação, o uso do termo sistema, que se configurou como uma espécie de termo primitivo não carecendo, pois, de definição. Daí sua polissemia com as imprecisões e confusões decorrentes, o que nos impõe a exigência de examinar, preliminarmente, o significado da expressão 'sistema educacional'. Convivemos diariamente com expressões como 'sistema federal de ensino', 'sistema oficial', 'sistema público', 'sistema escolar', 'sistema de ensino superior' etc. Na verdade, porém, o uso dessas expressões é impróprio; um exame mais detido revelará que, em todos esses casos, se trata propriamente do sistema educacional, considerado sob este ou aquele prisma, nesse ou naquele aspecto.

Na base desse uso difuso do conceito de sistema na educação está a noção de que o termo 'sistema' denota conjunto de elementos, isto é, a reunião de várias unidades formando um todo. Daí a assimilação do conceito de sistema educacional a conjunto de unidades escolares ou de rede de instituições de ensino. Assim, normalmente quando se fala em 'sistema público de ensino', o que está em causa é o conjunto das instituições públicas de ensino; quando se fala em sistema particular de ensino, trata-se da rede de escolas particulares; ao se falar em sistema superior de ensino, sistema de ensino profissional, sistema de ensino primário, igualmente a referência são as redes de escolas superiores, profissionais ou primárias e assim por diante.

Mas é preciso considerar que o conceito de sistema não se resume à idéia de rede de escolas. Para lá dessa acepção, o termo sistema denota um conjunto de atividades que se cumprem tendo em vista determinada finalidade. E isso implica que as referidas atividades são organizadas segundo normas decorrentes dos valores que estão na base da finalidade preconizada. Assim, sistema implica organização sob normas próprias (o que lhe confere um elevado grau de autonomia) e comuns (isto é, que obrigam a todos os seus integrantes).

Nas sociedades modernas a instância dotada de legitimidade para legislar, isto é, para definir e estipular normas comuns que se impõem a toda a coletividade, é o Estado. Daí que, a rigor, só se pode falar em sistema, em sentido próprio, na esfera pública. Por isso as escolas particulares integram o sistema quando fazem parte do sistema público de ensino, subordinandose, em conseqüência, às normas comuns que lhe são próprias. Assim, é só por analogia que se pode falar em 'sistema particular de ensino'. O abuso da analogia resulta responsável por boa parte das confusões e imprecisões que 
cercam a noção de sistema, dando origem a expressões como sistema público ou particular de ensino, sistema escolar etc. Ora, a expressão 'sistema público de educação' é pleonástica porque o sistema de ensino só pode ser público. Já a expressão 'sistema particular de ensino' é contraditória porque as entidades privadas não têm o poder de instituir sistemas educacionais. Em verdade, a atitude que tem prevalecido entre os educadores em geral e especialmente entre os legisladores tem sido a de evitar a questão relativa ao esclarecimento preciso do conceito de sistema, considerando-o como algo constantemente referido, mas cujo sentido permanece sempre implícito, supostamente compreendido, mas jamais assumido explicitamente.

Até a atual Lei de Diretrizes e Bases da Educação Nacional (LDB), aprovada em 20 de dezembro de 1996, havia no Brasil apenas duas modalidades de sistemas de ensino: o sistema federal, que abrangia os territórios federais e tinha caráter supletivo em relação aos estados; e os sistemas estaduais e do distrito federal. Nesse contexto, as escolas de educação básica, públicas e particulares, integravam os respectivos sistemas estaduais. Já as escolas superiores, públicas e particulares, integravam o sistema federal subordinando-se, pois, às normas fixadas pela União. Neste último caso a legislação admitia a possibilidade do sistema federal delegar aos sistemas estaduais a jurisdição sobre as escolas superiores, desde que se tratasse de Estado com tradição consolidada no âmbito do ensino superior.

Cabe observar que as dificuldades em relação a esse tema decorrem já do próprio texto constitucional. Tudo indica que os constituintes procederam nesse assunto segundo aquela atitude acima descrita, pressupondo tacitamente o significado de sistema, mas sem compreendê-lo de forma rigorosa e clara. Com isso, inadvertidamente, introduziram no texto, por analogia, o conceito de sistema municipal de ensino.

Ora, a própria Constituição, ao prescrever no artigo 22, inciso XXIV, que compete privativamente à União legislar sobre diretrizes e bases da educação nacional; que compete à União, aos Estados e ao Distrito Federal legislar concorrentemente sobre educação, cultura, ensino e desporto (artigo 24, inciso IX); e que é competência comum da União, dos Estados, do Distrito Federal e dos Municípios proporcionar os meios de acesso à cultura, à educação e à ciência (artigo 23, inciso V), não estendeu aos municípios a competência para legislar em matéria de educação. Portanto, não tendo autonomia para baixar normas próprias sobre educação ou ensino, os municípios estariam constitucionalmente impedidos de instituir sistemas próprios, isto é, municipais, de educação ou de ensino. Não obstante, o texto constitucional deixa margem, no artigo 211 , para que se possa falar em sistemas de ensino dos municípios quando estabelece que “a União, os Estados, o Distrito Federal e os Municípios organizarão, em regime de colaboração, os seus sistemas de ensino". 
Como interpretar esse dispositivo? Estaria ele afirmando claramente a competência dos municípios para instituir os respectivos sistemas de ensino? Mas então, por que não se estendeu aos municípios, de forma explícita, a competência para legislar em matéria de educação?

Observe-se que nessa passagem da Constituição Federal não aparece a expressão "os respectivos sistemas de ensino", mas "os seus sistemas de ensino". Ora, o adjetivo 'respectivos' denota univocamente 'de cada um' enquanto que a palavra 'seus' pode significar tanto 'de cada um' como 'deles', isto é, os sistemas de ensino da União, estados e municípios.

Será que, no citado artigo 211 , o acento deve ser posto na competência individual de cada ente federativo ou no regime de colaboração entre eles? Ou seja: o plural 'sistemas de ensino' deve ser lido como significando que cada um organiza o respectivo sistema de ensino ou estaria significando que a organização dos sistemas de ensino pressupõe sempre a colaboração entre os vários entes federados? Assim, no Distrito Federal, que não é constituído por municípios, a organização do sistema de ensino implicaria apenas a colaboração entre a União e o Distrito Federal. Já nos estados essa organização envolveria a colaboração entre a União, o estado e os seus municípios.

Por outro lado, o termo 'sistema' é utilizado em educação de forma equívoca assumindo, pois, diferentes significados. Ao que tudo indica, o artigo 211 da Constituição Federal de 1988 estaria tratando da organização das redes escolares que, no caso dos municípios, apenas por analogia são chamadas aí de sistemas de ensino. Com efeito, sabe-se que é muito comum a utilização do conceito de sistema de ensino como sinônimo de rede de escolas. Daí falar-se em sistema estadual, sistema municipal, sistema particular etc., isto é, respectivamente, rede de escolas organizadas e mantidas pelos estados, pelos municípios ou pela iniciativa particular. Obviamente, cabe aos municípios manter escolas, em especial de educação infantil e de ensino fundamental o que, aliás, está prescrito expressamente no inciso VI do artigo 30 da Constituição Federal de 1988: “compete aos Municípios: VI manter, com a cooperação técnica e financeira da União e do Estado, programas de educação pré-escolar e de ensino fundamental." É de se notar, por outro lado, que não consta desse artigo 30 que trata das competências dos municípios, a prerrogativa de "legislar sobre educação, cultura, ensino e desporto" como ocorre com a União, estados e Distrito Federal. Portanto, numa interpretação estrita do que está expresso no texto da Constituição Federal em vigor, os municípios não disporiam da faculdade de instituir sistemas próprios de ensino, já que isto entraria em conflito com o disposto no Título III da Constituição. Conseqüentemente, não haveria lugar para a instituição de sistemas municipais de ensino. As escolas municipais integrariam, via de regra, os sistemas estaduais de ensino subordinando-se, pois, às normas estabelecidas pelos respectivos estados. 
O texto da nova LDB, entretanto, procurou contornar a dificuldade apontada, ultrapassando a ambigüidade do texto constitucional e estabelecendo com clareza a existência dos sistemas municipais de ensino. Para tanto, além do artigo 211 ("A União, os Estados e os Municípios organizarão em regime de colaboração os seus sistemas de ensino"), a LDB terá certamente buscado respaldo nos incisos I e II do artigo 30 da Constituição Federal que afirmam, respectivamente, a competência dos municípios para "legislar sobre assuntos de interesse local" e "suplementar a legislação federal e a estadual no que couber". Assim, o inciso III do artigo 11 da LDB estipula que cabe aos municípios "baixar normas complementares para o seu sistema de ensino". Isto posto, ainda que do ponto de vista da hermenêutica constitucional se possa argüir contra a constitucionalidade do disposto na LDB, já que, se os constituintes quisessem, de fato, estender essa competência aos municípios o teriam feito expressamente como o fizeram em relação aos estados e ao Distrito Federal, já não pairam dúvidas, à luz do texto da LDB, quanto à competência legal dos municípios para instituir os respectivos sistemas de ensino. Conclui-se, então, que a definição clara da competência dos municípios para instituir os próprios sistemas de ensino flui da Lei de Diretrizes e Bases da Educação Nacional e não da Constituição Federal.

Admitida a possibilidade da organização de sistemas municipais de ensino, a questão daí decorrente diz respeito às condições para a sua efetivação. E sobre isso a LDB revelou uma certa cautela ao prescrever, no parágrafo único do artigo 11, que "os municípios poderão optar, ainda, por se integrar ao sistema estadual de ensino ou compor com ele um sistema único de educação básica".

Com certeza a LDB introduziu a possibilidade de opção à luz de duas evidências, uma no plano formal e outra no plano real. Do ponto de vista formal, levou em conta a ambigüidade da Constituição, como já se mostrou. Do ponto de vista real, considerou as dificuldades técnicas e financeiras que muitos municípios teriam para organizar a curto ou mesmo a médio prazo os seus sistemas de ensino. É de se notar que o reconhecimento dessa limitação está expresso também no texto constitucional quando, ao estabelecer no inciso VI do artigo 30 a competência inequívoca dos municípios de manter programas de educação pré-escolar e de ensino fundamental, acrescenta que isso será feito com a cooperação técnica e financeira da União e do estado.

E a questão do sistema nacional de educação? Como se põe no Brasil? Para abordá-la, devemos começar pelos obstáculos à sua construção. Entramos, assim, no tema específico deste ensaio: os desafios que precisam ser enfrentados caso queiramos, de fato, instituir um sistema nacional de educação no Brasil. 


\section{A histórica resistência à manutenção da educação pública no Brasil}

Ao iniciar sua obra educativa no Brasil em 1549 os jesuítas cumpriam mandato de D. João III, cabendo à coroa manter o ensino por eles ministrado. Mas o rei enviava verbas para a manutenção e a vestimenta dos jesuítas; não para construções. Então, os recursos que chegavam eram aplicados no colégio da Bahia e, como relata o padre Manuel da Nóbrega, em carta de agosto de 1552, "nós no vestido remediamo-nos com o que ainda do reino trouxemos, porque a mim ainda me serve a roupa com que embarquei... e no comer vivemos por esmolas" (HUE, 2006, p. 68). Essa situação foi contornada a partir de 1564 com o plano da redízima que destinava dez por cento de todos os impostos arrecadados da colônia brasileira à manutenção dos colégios jesuíticos.

No período seguinte (1759-1827), as reformas pombalinas da instrução pública instituíram as 'aulas régias' a serem mantidas pela Coroa por meio do 'subsídio literário' criado em 1772. Mas a dificuldade de cobrança desse tributo na colônia não permitiu a adequada manutenção do ensino.

Com a independência política, foi instalado o Primeiro Império que fez aprovar, em 15 de outubro de 1827, a lei das escolas de primeiras letras, cujo artigo primeiro estabelecia: "em todas as cidades, vilas e lugares mais populosos haverão [sic] as escolas de primeiras letras que forem necessárias" (Tambara e Arriada, 2005, p. 23). Mas essa lei permaneceu letra morta. E o Ato Adicional à Constituição do Império, promulgado em 1834, colocou o ensino primário sob a jurisdição das Províncias, desobrigando o Estado Nacional de cuidar desse nível de ensino. Considerando que as províncias não estavam equipadas financeiramente e nem tecnicamente para promover a difusão do ensino, o resultado foi que atravessamos o século XIX sem que a educação pública fosse incrementada.

Durante os 49 anos correspondentes ao Segundo Império, entre 1840 e 1888, a média anual dos recursos financeiros investidos em educação foi de $1,80 \%$ do orçamento do governo imperial, destinando-se, para a instrução primária e secundária, a média de 0,47\% (Chaia, 1965, p. 129-131). Era, pois, um investimento irrisório como constatou Rui Barbosa em 1882: "O Estado, no Brasil, consagra a esse serviço apenas 1,99\% do orçamento geral, enquanto as despesas militares nos devoram 20,86\%" (Chaia, 1965, p. 103). Dessa forma, o sistema nacional de ensino não se implantou e o país foi acumulando um grande déficit histórico em matéria de educação.

Ao longo da Primeira República o ensino permaneceu praticamente estagnado, o que pode ser ilustrado com o número de analfabetos em relação à população total, que se manteve no índice de 65\% entre 1900 e 1920, sendo que o seu número absoluto aumentou de 6.348.869, em 1900, para 11.401.715, em 1920. A partir da década de 1930, com o incremento da 
industrialização e urbanização, começa a haver, também, um incremento correspondente nos índices de escolarização, sempre, porém, em ritmo aquém do necessário à vista dos escassos investimentos. Assim, os investimentos federais em ensino passam de 2,1\%, em 1932, para 2,5\%, em 1936; os estaduais se reduzem de $15,0 \%$ para $13,4 \%$ e os municipais se ampliam de $8,1 \%$ para $8,3 \%$ no mesmo período (Ribeiro, 2003, p. 117). Isso não obstante a Constituição de 1934 ter determinado que a União e os municípios deveriam aplicar nunca menos de $10 \%$ e os estados $20 \%$ da arrecadação de impostos "na manutenção e desenvolvimento dos sistemas educacionais" (artigo 156). Essa vinculação orçamentária foi retirada na Constituição de 1937, do Estado Novo, e foi retomada na Carta de 1946, que fixou em $20 \%$ a obrigação mínima dos estados e municípios, e $10 \%$ da União. No entanto, em 1955 tínhamos os seguintes índices: União, 5,7\%; estados, 13,7\%; municípios, 11,4\%.

A Constituição do regime militar, de 1967 e a Emenda de 1969, voltaram a excluir a vinculação orçamentária. Constata-se, então, que o orçamento da União para educação e cultura caiu de 9, 6\%, em 1965, para 4,31\%, em 1975.

A atual Constituição, promulgada em 1988, restabeleceu a vinculação fixando $18 \%$ para a União e $25 \%$ para estados e municípios. E, como o texto constitucional estabelece esses percentuais mínimos em relação à "receita resultante de impostos", além do desrespeito contumaz à norma estabelecida na Carta Magna, encontrou-se, especialmente a partir do governo FHC, um outro mecanismo de burlar essa exigência. Passou-se a criar novas fontes de receita nomeando-as, porém, não com a palavra 'imposto', mas utilizando o termo 'contribuição', como são os casos da Cofins (Contribuição para o Financiamento da Seguridade Social), CPMF (Contribuição Provisória sobre Movimentação Financeira), Cide (Contribuição sobre Intervenção no Domínio Econômico). A essas receitas, como não recebem o nome de impostos, não se aplica a vinculação orçamentária constitucional dirigida à educação. Além disso, também a partir do governo FHC, instituiu-se a DRU (Desvinculação das Receitas da União), que permite subtrair $20 \%$ das vinculações orçamentárias.

Tomemos, então, para considerar a situação atual, um índice de caráter global e, ao menos por enquanto, ainda não atingido pelos truques e 'jeitinhos' em que são mestras as nossas elites econômicas e políticas: o PIB (Produto Interno Bruto), isto é, a soma de todas as riquezas produzidas pelo país. Calculado pela nova metodologia do IBGE, o PIB brasileiro em 2006 foi de 2 trilhões e 322 bilhões de reais. Isso significa que, levando-se em conta a informação do próprio MEC de que o Brasil gasta em educação, atualmente, 4,3\% do PIB, os gastos para 2007 deveriam ser da ordem de 99 bilhões e 846 milhões de reais. Assim, mesmo descontando-se os gastos 
com ensino superior, que não chegam a $1 \%$ do PIB, o total de 43 bilhões e 100 milhões previstos para o Fundeb em 2007 está muito aquém do que corresponderia a esse ano. Com efeito, mesmo que fossem destinados 23 bilhões ( $1 \%$ do PIB de 2006) ao ensino superior, o montante a ser destinado à educação básica seria de 76 bilhões e 800 milhões, muito superior, portanto, ao valor de 43 bilhões e 100 milhões programados para 2007. E esse é o montante de que dispõe o MEC para o novo PDE porque, como se anunciou, apenas se prevê o acréscimo de um bilhão para atender aos programas específicos anunciados pelo Plano. Está aí, me parece, a grande limitação do PDE, o Plano de Desenvolvimento da Educação, lançado oficialmente com as devidas pompas e circunstâncias no dia 24 de abril de 2007.

\section{A descontinuidade nas políticas educativas}

A outra característica estrutural da política educacional brasileira, que opera como um desafio para a construção do sistema nacional de educação, é a descontinuidade. Esta se manifesta de várias maneiras, mas se tipifica mais visivelmente na pletora de reformas de que está povoada a história da educação brasileira. Essas reformas, vistas em retrospectiva de conjunto, descrevem um movimento que pode ser reconhecido pelas metáforas do ziguezague ou do pêndulo. A metáfora do ziguezague indica o sentido tortuoso, sinuoso das variações e alterações sucessivas observadas nas reformas; o movimento pendular mostra o vaivém de dois temas que se alternam seqüencialmente nas medidas reformadoras da estrutura educacional.

Desde a primeira fase do Brasil independente as reformas se sucedem: lei das escolas de primeiras letras, em 1827; ato adicional de 1834; reforma Couto Ferraz, de 1854; Leôncio de Carvalho em 1879, sem contar os vários projetos de reforma apresentados no Parlamento no final do império que não chegaram a vingar, como os de Paulino de Souza, em 1869; de João Alfredo, em 1871; de Rui Barbosa, em 1882; de Almeida Oliveira, também em 1882; e o do Barão de Mamoré, em 1886. Observe-se que prevalece a tendência em nomear as reformas pelos seus proponentes, em geral ministros da pasta de instrução pública ou da educação, a indicar que quem chega ao poder procura imprimir sua marca, desfazendo o que estava em curso e projetando a idéia de que com ele, finalmente, o problema será resolvido.

Esse movimento prossegue no período republicano patenteando-se melhor aí o caráter pendular, pois se uma reforma promove a centralização, a seguinte descentraliza para que a próxima volte a centralizar a educação, e assim sucessivamente. Se uma reforma se centra na liberdade de ensino, logo será seguida por outra que salientará a necessidade de regulamentar 
e controlar o ensino. Uma reforma colocará o foco do currículo nos estudos científicos e será seguida por outra que deslocará o eixo curricular para os estudos humanísticos.

No plano federal o regime republicano expressou a tensão na política educacional oscilando entre a centralização (oficialização) e descentralização (desoficialização). Após a reforma Benjamin Constant, de 1890, que procurou introduzir os estudos científicos e atenuar o excesso de liberdade que marcou a reforma Leôncio de Carvalho, tivemos o Código Epitácio Pessoa, em 1901. Esse código ratificou o princípio de liberdade de ensino da reforma Leôncio de Carvalho, equiparou as escolas privadas às oficiais e acentuou a parte literária dos currículos. Mas a reforma Rivadávia Correa, em 1911, volta a reforçar a liberdade de ensino e a desoficialização, além de retomar a orientação positivista, tentando imprimir um caráter prático à orientação dos estudos. Diante das conseqüências desastrosas, uma nova reforma, a de Carlos Maximiliano, instituída em 1915, reoficializou o ensino e introduziu o exame vestibular a ser realizado nas próprias faculdades, podendo a ele se submeter apenas os candidatos que dispusessem de diploma de conclusão do curso secundário. O ciclo das reformas federais do ensino na Primeira República se fecha, em 1925, com a reforma João Luís Alves/Rocha Vaz. Considerando que ela se encontra em pleno centro da última década da Primeira República quando, sobre a base das transformações econômicas e sociais em curso, a estrutura de poder vigente passa a ser amplamente contestada, essa nova reforma irá reforçar e ampliar os mecanismos de controle instituídos pela reforma Carlos Maximiliano.

À descentralização representada pelo protagonismo das reformas de ensino estaduais que marcaram a década de 1920 seguiu-se um processo de centralização com as reformas de âmbito nacional encabeçadas por Francisco Campos, em 1931, com o ciclo das reformas Capanema entre 1942 e 1946, com a LDB de 1961 e com a legislação do regime militar nos anos de 1968 e 1971. Mas nesse mesmo período os liberais adeptos da pedagogia nova defenderam a descentralização do ensino, impedindo que a legislação no âmbito federal consagrasse o princípio organizacional do sistema nacional de educação.

A era atual tem início com a Constituição de 1988 e, após algumas alterações da legislação do período militar durante a Nova República, tivemos as reformas dos anos de 1990 em cujo centro se encontra a nova LDB, de 1996, e o Plano Nacional de Educação aprovado em janeiro de 2001.

A marca da descontinuidade na política de educação atual se faz presente na meta, sempre adiada, de eliminação do analfabetismo e universalização do ensino fundamental. O Brasil chegou ao final do século XX sem resolver um problema que os principais países, inclusive nossos vizinhos Argentina, Chile e Uruguai, resolveram na virada do século XIX para o XX: 
a universalização do ensino fundamental, com a conseqüente erradicação do analfabetismo. Para enfrentar esse problema, a Constituição de 1988 previu, nas disposições transitórias, que o Poder Público nas suas três instâncias (a União, os estados e os municípios) deveriam, pelos dez anos seguintes, destinar $50 \%$ do orçamento educacional para essa dupla finalidade. Isso não foi feito. Quando esse prazo estava vencendo, o governo criou o Fundef, com prazo de mais dez anos para essa mesma finalidade; e a LDB, por sua vez, instituiu a década da educação; seguiu-se a aprovação, em 2001, do Plano Nacional de Educação (PNE), que também se estenderia por dez anos. No final de 2006, ao se esgotarem os dez anos do prazo do Fundef, foi instituído o Fundeb, com prazo de 14 anos, ou seja, até 2020. Agora, quando mais da metade do tempo do PNE já passou, vem um novo plano, o Plano de Desenvolvimento da Educação, estabelecer um novo prazo, desta vez de 15 anos, projetando a solução do problema para 2022. Nesse diapasão, já podemos conjecturar sobre um novo plano que será lançado em 2022, prevendo, quem sabe, mais 20 anos para resolver o mesmo problema.

\section{A resistência no nível das idéias}

A idéia de sistema nacional de ensino foi pensada no século XIX como forma de organização prática da educação, constituindo-se numa ampla rede de escolas abrangendo todo o território da nação e articuladas entre si segundo normas comuns e com objetivos também comuns. A sua implantação requeria, pois, preliminarmente, determinadas condições materiais dependentes de significativo investimento financeiro, o que se constitui no primeiro desafio, conforme já foi analisado. Além disso, a implantação do sistema nacional de educação requeria também determinadas condições políticas, o que igualmente já foi analisado ao se abordar, no segundo desafio, a questão da descontinuidade nas reformas educacionais.

Mas, além das limitações materiais e políticas, cumpre considerar, também, o problema relativo à mentalidade pedagógica. Entendida como a unidade entre a forma e o conteúdo das idéias educacionais, a mentalidade pedagógica articula a concepção geral do homem, do mundo, da vida e da sociedade com a questão educacional. Assim, numa sociedade determinada, dependendo das posições ocupadas pelas diferentes forças sociais, estruturam-se diferentes mentalidades pedagógicas. Na sociedade brasileira da segunda metade do século XIX três mentalidades pedagógicas se delinearam com razoável nitidez: as mentalidades tradicionalista, liberal e cien-

tificista. Destas, as duas últimas correspondiam ao espírito moderno que se expressava no laicismo do Estado, da cultura e da educação (Barros, 1959, p. 21-36). Nesse contexto, era de se esperar que os representantes dessas 
mentalidades de tipo moderno, empenhados na modernização da sociedade brasileira, viessem a formular as condições e prover os meios para a realização da idéia de sistema nacional de educação. No entanto, a mentalidade cientificista de orientação positivista, declarando-se adepta da completa 'desoficialização' do ensino, acabou por se converter em mais um obstáculo à realização da idéia de sistema nacional de ensino. Na mesma direção se comportou a mentalidade liberal que, em nome do princípio de que o Estado não tem doutrina, chegava a advogar o seu afastamento do âmbito educativo.

Nessas circunstâncias, embora os debates do final do império apontassem na direção da construção de um sistema nacional de ensino colocando-se a instrução pública, com destaque para as escolas primárias, sob a égide do governo central, o advento do regime republicano não corroborou essa expectativa. Seja pelo argumento de que, se no Império, que era um regime político centralizado, a instrução estava descentralizada, a fortiori na República Federativa, um regime político descentralizado, a instrução popular deveria permanecer descentralizada; seja pela força da mentalidade positivista no movimento republicano; seja pela influência do modelo norte-americano; seja principalmente pelo peso econômico do setor cafeeiro que desejava a diminuição do poder central em favor do mando local, o certo é que o novo regime não assumiu a instrução pública como uma questão de responsabilidade do governo central, o que foi legitimado na primeira Constituição republicana. Ao estipular, no artigo 35, que incumbe ao Congresso Nacional, ainda que não privativamente, "criar instituições de ensino superior e secundário nos Estados" (inciso $3^{\circ}$ ) e "prover a instrução secundária no Distrito Federal" (inciso $4^{\circ}$ ), a Constituição, embora omissa quanto à responsabilidade sobre o ensino primário, delegava aos estados competência para legislar e prover esse nível de ensino.

A partir da década de 1930, com o avanço da industrialização e urbanização do país, a educação começa a ser tratada como questão nacional. No entanto, apesar do Manifesto dos Pioneiros da Educação Nova ter advogado a formulação de um plano de reconstrução educacional convergente com a idéia de sistema nacional de educação, os renovadores, organizados no âmbito da Associação Brasileira de Educação (ABE), se posicionaram recorrentemente em favor da descentralização. Isto os levou a preconizar, no projeto de LDB elaborado em 1947, a instituição de sistemas estaduais de ensino, elidindo a questão do sistema nacional. Levando mais longe essa posição, Anísio Teixeira se manifestou como um fervoroso adepto da municipalização chegando, mesmo, a preconizar a vinculação distrital. Essa posição fica clara quando ele considera que os sistemas educacionais não são algo abstrato referido à população de todo o país, "mas conjuntos de escolas vinculadas às unidades da população e, em rigor, a cada comunidade 
local", concluindo que sua vinculação "ao município é o mínimo que temos de admitir - pois poderíamos considerá-lo vinculado ao distrito" (Teixeira, 1962, p. 101). Com certeza essa posição decorre do comunitarismo americano presente no ideário pedagógico de Dewey. Com todo o respeito pela enorme folha de serviços prestados à educação brasileira, o que o torna o único brasileiro a merecer o título de 'estadista da educação', essa visão de Anísio Teixeira não deixou de ter efeitos negativos para o ensino em nosso país. Essa resistência dos liberais à idéia de sistema nacional de educação persistirá nos anos subseqüentes, estendendo-se até os dias de hoje sendo, agora, de certo modo exacerbada no contexto do chamado neoliberalismo.

Conclui-se, pois, que as dificuldades para a realização da idéia de sistema nacional de ensino se manifestaram tanto no plano das condições materiais e políticas como no âmbito da mentalidade pedagógica. Assim, o caminho da implantação dos respectivos sistemas nacionais de ensino, por meio do qual os principais países do Ocidente lograram universalizar o ensino fundamental e erradicar o analfabetismo, não foi trilhado pelo Brasil. $\mathrm{E}$ as consequiências desse fato se projetam ainda hoje, deixando-nos um legado de agudas deficiências no que se refere ao atendimento das necessidades educacionais do conjunto da população.

\section{A resistência no plano legal}

Do ponto de vista lógico resulta evidente a relação de implicação entre os conceitos de 'lei de diretrizes e bases da educação nacional' e de 'sistema nacional de educação'. Quando a Constituição determina que a União estabeleça as diretrizes e bases da educação nacional, obviamente ela está pretendendo com isso que a educação, em todo o território do país, seja organizada segundo diretrizes comuns e sobre bases também comuns. E a organização educacional com essas características é o que se chama 'sistema nacional de educação'. Essa situação se encontra ainda mais tipificada no caso da Constituição atual que estabeleceu, no artigo 211, o regime de colaboração.

O fato de que, por se tratar de uma República Federativa, a Constituição reconheça também a competência dos estados para legislar em matéria de educação, em nada afeta o enunciado anterior. Com efeito, sistema não é unidade da identidade, uma unidade monolítica, indiferenciada, mas unidade da diversidade, um todo que articula uma variedade de elementos que, ao se integrarem ao todo, nem por isso perdem a própria identidade. Ao contrário, participam do todo, integram o sistema, na forma das respectivas especificidades. Em outros termos: uma unidade monolítica é tão avessa à idéia de sistema como uma multiplicidade desarticulada. Em verdade, 
sistematizar significa reunir, ordenar, articular elementos enquanto partes de um todo. E esse todo articulado é o sistema.

Considerar, pois, como inconstitucional a inclusão do tema relativo ao sistema nacional de educação na Lei de Diretrizes e Bases da Educação Nacional é uma contradictio in terminis, é a própria contradição lógica. E isto porque a LDB implica o sistema.

Como demonstrei em outro trabalho (Saviani, 2008), há uma estreita relação entre a LDB e a sistematização da educação. A educação assistemática não é objeto de legislação específica. Veja-se, por exemplo, as questões referentes ao pátrio poder, às diversões públicas etc., que podem ser consideradas atividades educativas segundo o próprio conceito adotado no Título I da nova LDB; no entanto, tais questões são reguladas pelo Código Civil. Quando, no entanto, se pensa numa lei específica para a educação, é porque se está visando à sua sistematização e não apenas à sua institucionalização. Antes de haver leis de educação, havia instituições educativas. Isso não implica, entretanto, a vinculação necessária da sistematização à legislação, ou seja: não é necessário que haja lei específica de educação para que haja educação sistematizada; esta poderá existir mesmo não existindo aquela. O que fica claro é a vinculação necessária da lei específica de educação à sistematização. Tal lei visará consolidar o sistema ou reformá-lo (caso exista), ou então instituí-lo, ou pelo menos determinar as condições para que ele seja criado (caso não exista).

Ora, em se tratando de uma lei que se propõe a fixar as Diretrizes e Bases da Educação Nacional, mais ainda se impõe a conclusão acima apresentada. Com efeito, se por diretrizes e bases se entendem fins e meios, ao serem estes definidos em termos nacionais pretende-se não apenas indicar os rumos para onde se quer caminhar, mas organizar a forma, isto é, os meios através dos quais os fins serão atingidos. E a organização intencional dos meios com vistas a se atingir os fins educacionais preconizados em âmbito nacional, eis o que se chama 'sistema nacional de educação'.

Não obstante essa evidência, na trajetória da nova LDB houve aqueles protagonistas que incidiram nessa contradictio in terminis, opinando pela inconstitucionalidade do Título relativo ao Sistema Nacional de Educação que integrava o Substitutivo Jorge Hage. Em conseqüência, a referida denominação foi substituída por esta outra: Organização da Educação Nacional.

Em verdade, essa resultou uma solução de tipo nominalista, já que os que a postularam se satisfizeram com a mudança do nome sem se preocupar com a manutenção do mesmo conteúdo. O viés nominalista talvez tenha tido mesmo algum peso, pois se argumentava que na Constituição não aparecia a expressão 'sistema nacional de educação', mas apenas 'sistemas de ensino'. Aos que defendiam o sistema nacional, em contrapartida, 
preocupava exatamente o seu conteúdo, secundarizando a terminologia, o que permitiu, nas negociações, que se abrisse mão da denominação.

Efetivamente, no projeto aprovado na Câmara, o Capítulo que tratava Da Organização da Educação Nacional preservava os mecanismos básicos do sistema entre os quais desempenhava papel central o Conselho Nacional de Educação (CNE), secundado pelo Fórum Nacional de Educação. Com a prevalência do Substitutivo Darcy Ribeiro manteve-se a denominação (Organização da Educação Nacional), mas o conteúdo foi fortemente alterado.

O Título IV - Da Organização da Educação Nacional, da lei finalmente aprovada, está calcado no Substitutivo Darcy Ribeiro. Em conseqüência, desaparece o Fórum Nacional de Educação, assim como a regulamentação criteriosa dos artigos 209 e 213 da Constituição. Recorde-se que esses artigos versam respectivamente sobre a liberdade de ensino conferida à iniciativa privada e a destinação de recursos públicos às instituições de ensino de caráter comunitário, confessional e filantrópico.

O Conselho Nacional de Educação, que estava inteiramente ausente do primeiro projeto Darcy Ribeiro, no texto da lei é apenas mencionado no parágrafo $1^{\circ}$ do inciso IX do artigo $9^{\circ}$. E isso era inevitável, uma vez que já se encontrava em vigor, homologada pelo Congresso, a medida provisória originária do presidente Itamar Franco e reeditada por Fernando Henrique. Foi excluído, assim, o detalhamento referente à composição e atribuições do CNE que figurava no projeto aprovado pela Câmara.

A razão invocada para a exclusão do Conselho Nacional de Educação do texto da LDB foi a denominada 'inconstitucionalidade por vício de iniciativa'. Remete-se, então, ao artigo 6l, parágrafo $1^{\circ}$, alínea 'e' (são de iniciativa privativa do presidente da República as leis de "criação, estruturação e atribuições dos Ministérios e órgãos da administração pública") e ao artigo 84, VI ("compete privativamente ao Presidente da República: dispor sobre a organização e o funcionamento da administração federal, na forma da lei") e XXV ("prover e extinguir os cargos públicos federais, na forma da lei").

Entendo que a interpretação supra não é inteiramente tranqüila. Em verdade, ela parte do entendimento prévio do Conselho Nacional de Educação como sendo meramente um órgão administrativo federal. Na concepção de LDB que prevaleceu na Câmara, o CNE tinha um outro caráter: era uma instância com funções deliberativas no âmbito da educação análogas àquelas exercidas pelo Legislativo e Judiciário no âmbito da sociedade como um todo.

Fica claro, no entanto, que não era esse, propriamente, o problema. Digamos que, de fato, estava configurado o 'vício de iniciativa'. Isso não impediu que o governo Itamar Franco, através do ministro da Educação 
Murílio Hingel referendasse o CNE tal como proposto no projeto da LDB podendo, se necessário, sanar o vício de iniciativa como de fato o fez quando, ao fechar o Conselho Federal de Educação, instituiu, por medida provisória, o Conselho Nacional de Educação.

A questão, aí, era o caráter deliberativo do CNE que, segundo a interpretação do governo Collor como do governo FHC, secundarizaria o MEC na tarefa de formular a política nacional de educação. O que se pretendia, no entanto, era instituir uma instância com representação permanente da sociedade civil para compartilhar com o governo a formulação, acompanhamento e avaliação da política educacional. Tanto assim que na versão aprovada pela Câmara metade dos membros do CNE era escolhida pelo presidente da República.

E deve-se destacar que com esse encaminhamento se pretendia evitar a descontinuidade que tem marcado a política educacional, o que conduz ao fracasso as tentativas de mudança, pois tudo volta à estaca zero a cada troca de equipe de governo. Na verdade, cada governante quer imprimir a própria marca, quer fazer a 'sua' reforma. Com isso, interrompe o que havia sido iniciado na gestão anterior e a educação fica marcando passo, já que se trata de um assunto que só pode ser equacionado satisfatoriamente a médio e longo prazo, jamais a curto prazo. E as conseqüências recaem sobre a população que vê indefinidamente adiado o atendimento de suas necessidades educacionais.

O Conselho Nacional de Educação, pensado como um órgão revestido das características de autonomia, representatividade e legitimidade, como uma instância permanente e renovada por critérios e periodicidade distintos daqueles que vigoram no âmbito da política partidária, estaria, senão imune, pelo menos não tão vulnerável aos interesses da política miúda.

Infelizmente, mais uma vez a vitória foi da política miúda, o que nos deixa à mercê do vaivém da política educacional.

É certo que a proposta do CNE como órgão central do sistema nacional de educação não estava isenta de problemas. Mas a simples impossibilidade de submetê-la ao teste da experiência configura uma perda que pode postergar por mais alguns anos o enfrentamento dos nossos problemas educacionais aumentando, assim, o já excessivo déficit histórico acumulado.

\section{Conclusão}

Procurou-se esboçar o quadro em que se situa o problema do sistema nacional de educação em nosso país. Diante desse quadro, o significado da retomada dessa questão no atual contexto não deixa de ser auspicioso, mas é forçoso também reconhecer que as dificuldades ainda persistem. 
Assim, permanece a questão da imprecisão. No prefácio à décima edição do livro Educação brasileira: estrutura e sistema, redigido em janeiro deste ano de 2008, observo que, na esteira do Plano de Desenvolvimento da Educação, lançado em 24 de abril de 2007, o próprio MEC induz à retomada da discussão sobre o sistema nacional de educação. Pela portaria $\mathrm{n}^{\circ} 11$, baixada pelo ministro no mesmo dia 24 de abril de 2007, foi constituída a Comissão Organizadora da Conferência Nacional de Educação Básica, realizada em abril de 2008, para a qual deveriam confluir as conferências estaduais de educação previstas, na mesma portaria, ocorridas no segundo semestre de 2007. E o regimento interno da Conferência Nacional da Educação Básica estabelece como primeiro objetivo "promover a construção de um Sistema Nacional Articulado de Educação". Por sua vez, o documento denominado "O Plano de Desenvolvimento da Educação: razões, princípios e programas", lançado pelo MEC, contempla, no ponto 3, "o plano de desenvolvimento da educação como horizonte do debate sobre o sistema nacional de educação", justificado com esta consideração: “a visão sistêmica da educação é a única compatível com o horizonte de um sistema nacional de educação..." (Brasil, 2008, p. 39).

Como se vê, o debate, já no seu lançamento, aparece eivado de problemas e imprecisões. Com efeito, formula-se o objetivo de construção de um sistema nacional de educação no âmbito de uma conferência nacional de educação básica. Por que não uma Conferência Nacional de Educação que, portanto, abrangesse, também, a educação superior? Dada a restrição do âmbito em que o problema é formulado surgem, também, enunciados do tipo 'sistema nacional de educação básica'. Ora, o sistema se refere ao conjunto que articula, num todo coerente, as várias partes que o integram. Como, então, falar de um sistema de educação básica se esta deveria ser, na verdade, uma das partes do sistema? Igualmente, resulta pleonástica a expressão 'sistema articulado de educação', que vem freqüentando os documentos, uma vez que só se pode falar em sistema se, efetivamente, suas partes estiverem articuladas. E no texto citado do MEC que apresenta as razões, princípios e programas do PDE estabelece-se uma aproximação da noção de sistema com o 'enfoque sistêmico'. No entanto, não podemos perder de vista que a organização dos sistemas nacionais de ensino antecede historicamente em mais de um século ao advento do chamado 'enfoque sistêmico'. Portanto, trata-se de coisas distintas. O enfoque sistêmico é um conceito epistemológico que está referido a uma determinada maneira de analisar os fenômenos, mais especificamente, ao método estrutural-funcionalista. Portanto, quando aplicado à educação, o referido enfoque diz respeito a um dos possíveis modos de se analisar o fenômeno educativo. Em contrapartida, a noção de sistema educacional tem caráter 
ontológico, pois se refere ao modo como o próprio fenômeno educativo é (ou deve ser) organizado.

Para além da questão conceitual, os desafios também persistem. Como foi evidenciado ao longo da exposição, o desafio econômico ligado ao financiamento da educação continua presente. Considerando-se que a fonte principal e quase exclusiva do financiamento do PDE está constituída pelo Fundeb, é preciso reconhecer que o Fundeb não representou aumento dos recursos financeiros. Ao contrário. Conforme foi divulgado no dia 20 de junho de 2007, na ocasião da sanção da lei que regulamentou o Fundeb, o número de estudantes atendidos pelo fundo passa de 30 milhões para 47 milhões, portanto, um aumento de $56,6 \%$. Em contrapartida, o montante do fundo passou de 35,2 bilhões para 48 bilhões, o que significa um acréscimo de apenas $36,3 \%$. Esse fundo passa a abarcar toda a educação básica sem que, em sua composição, entrem todos os recursos que estados e municípios devem destinar, por imperativo constitucional, à educação. O que estados e municípios farão com os $5 \%$ que lhes restam dos recursos educacionais? Se, em razão da criação do Fundeb, esses entes federativos se sentirem estimulados a investir em outros setores para além de suas responsabilidades prioritárias (educação infantil e ensino fundamental para os municípios e ensino fundamental e ensino médio para os estados), esses recursos, com certeza, farão falta para a manutenção da educação básica. Também a complementação da União não implicou acréscimo. Com efeito, antes a União deveria entrar com pelo menos $30 \%$ de seu orçamento. Ora, o orçamento do MEC para 2007, após o corte de 610 milhões imposto pela Fazenda, foi de 9 bilhões e 130 milhões. Logo, 30\% corresponderiam a 2 bilhões e 739 milhões. No entanto, a importância prevista como complementação da União para 2007 se limita a 2 bilhões. E, para 2008, esse desafio não só se mantém, como tende a ser agravado. Isso porque o governo já vem anunciando a necessidade de cortes no orçamento da educação para adequar as contas da União à extinção da CPMF. Não bastasse isso, um dos itens da reforma tributária que se pretende aprovar é a extinção do salário-educação, cujo montante superou, em 2007, a casa dos 7 bilhões de reais.

Mantém-se igualmente o desafio da descontinuidade, o que se patenteia no alto grau de fragmentação das ações que compõem o PDE e nas disputas políticas que marcam os partidos nas instâncias federal, estadual e municipal. Em conseqüência, persistem também os desafios ideológicos, pois a idéia de sistema nacional de educação permanece sujeita a considerável controvérsia, o que interfere no ordenamento legal que continua sendo um grande desafio para se chegar a uma normatização comum, válida para todo o país, condição indispensável à implantação do sistema nacional de educação. 


\section{Notas}

1 Professor Emérito da Universidade Estadual de Campinas (Unicamp), Campinas, São Paulo, Brasil. Doutor em Filosofia da Educação pela Pontifícia Universidade Católica de São Paulo (PUC-SP). Pós-doutor pela Universitá di Bologna (Itália). Coordenador Geral do Grupo Nacional de Estudos e Pesquisas "História, Sociedade e Educação no Brasil" (HISTEDBR). < dermevalsaviani@yahoo.com.br>

Correspondência: Universidade Estadual de Campinas, Faculdade de Educação, Departamento de Filosofia e História da Educação, Rua Bertrand Russell, 801, Barão Geraldo, Campinas, São Paulo, CEP 13.081-970, Caixa Postal 6120.

2 Adaptado da palestra proferida no "Ciclo de debates: a articulação entre a educação básica e a educação profissional - contribuições para a I Conferência Nacional de Educação Básica", realizado na Escola Politécnica de Saúde Joaquim Venâncio, Fiocruz, Rio de Janeiro, em 5 de março de 2008.

\section{Referências}

BARROS, Roque Spencer Maciel. A ilustração brasileira e a idéia de universidade. Boletim, n. 241, Faculdade de Filosofia, Ciências e Letras da USP. São Paulo, 1959.

BRASIL. Constituição da República Federativa do Brasil. São Paulo: Imprensa Oficial do Estado de São Paulo, 1988, 48 p.

BRASIL. Ministério da Educação. Plano de desenvolvimento da educação: razões, princípios e programas, p. 39, 2008. Disponível em: <http://portal.mec.gov.br/arquivos/ pdf/livromiolov4.pdf $>$. Acesso em: 1 mar. 2008.

CAMPANHOLE, Adriano; CAMPANHOLE, Hilton Lobo. Constituições do Brasil. 6. ed., São Paulo, Atlas, 1983.

CHAIA, Josephina. Financiamento escolar no segundo império. Marília: Faculdade de Filosofia, Ciências e Letras de Marília, 1965.

HUE, Sheila Moura. Primeiras cartas do Brasil (1551-1555). Rio de Janeiro: Jorge Zahar, 2006.
RIBEIRO, Maria Luísa S. História da educação brasileira. Campinas: Autores Associados, 2003.

SAVIANI, Dermeval. Educação brasileira: estrutura e sistema. 10. ed. Campinas: Autores Associados, 2008.

TAMBARA, Elomar; ARRIADA, Eduardo (Orgs.). Coletânea de leis sobre o ensino primário e secundário no periodo imperial brasileiro: Lei de 1827; Reforma Couto Ferraz - 1854; Reforma Leôncio de Carvalho 1879. Pelotas: Seiva, 2005.

TEIXEIRA, Anísio Spínola. Bases preliminares para o plano de educação relativo ao fundo nacional do ensino primário. Revista Brasileira de Estudos Pedagógicos. Rio de Janeiro, v. 38, n. 88, out./dez. 1962. p. 97-107.

\section{Recebido em 05/04/2008}

Aprovado em 30/05/2008 
